\title{
Association between Helicobacter Pylori and Hyperemesis Gravidarum
}

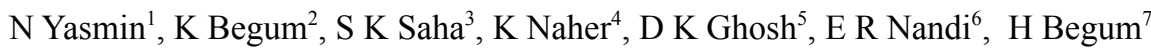

\begin{abstract}
Background: Hyperemesis gravidarum $(\mathrm{HG})$ is the severe form of the nausea \& vomiting in pregnancy and is associated with weight loss, ketonemia ,ketonuria ,electrolyte imbalances and profound volume depletion. Increased accumulation of fluid caused by elevated steroid hormones in pregnancy, a shift in $\mathrm{pH}$ and change of $\mathrm{pH}$ in the gastrointestinal tract could result in the manifestation of subclinical Helicobacter pylori (H. Pylori) infection. We therefore examined whether seropositivity for IgG antibodies to H. Pylori may be related to hyperemesis graviderum. Objective: To determine the association of H-pylori infection in hyperemesis graviderum patients. Methodology: A cross sectional study was conducted in the department of obstetrics and gynaecology, Dhaka medical college hospital from January 2007 to December 2008. Total 82 pregnant patients, 40 were hyperemesis gravidarum patients (Cases, group A) and 42 were normal pregnancy without hyperemesis graviderum (Control, group B) for admission and attending for routine ANC in OPD were selected. Purposive sampling method was followed as per inclusion and exclusion criteria. Evaluation of the patients was based on history, physical examination and investigation. Serum IgG antibody response to H.pylori antigen by ELISA were measured from every patients and analysed for its association with HG. Results: Most of the patients of this study were primi gravida, Group-A was $72.5 \%$ and Group-B was $66.7 \%$. Maximum number of women in both the groups belonged to lower socio-economic status (Group-A was $85 \%$ and Group-B was (76\%). Previous H/O hyperemesis gravidarum in the Group-A was $52.5 \%$ and Group-B was $07 \%(\mathrm{p}<.01)$, that is statistically highly significant. Antibody to Helicobactor pylori in serum was positive in Group-A 47.5\%, and Group-B 19\%. The difference was statistically significant. (p value-0.006). Conclusion: According to the findings of our study, H.pylori infection would seem to be an important associated factor in the exacerbation of $\mathrm{HG}$, but it does not seem to be the only cause of the disease. [J Shaheed Suhrawardy Med Coll 2016;8(1): 13-16]
\end{abstract}

Keywords: H-Pylori, Hyperemesis graviderum, Morning sickness.

\section{Introduction}

Nausea and vomiting (morning sickness) during pregnancy has a pervasive detrimental impact on women's family, social and professional lives ${ }^{1}$. It is associated with $50-90 \%$ of all pregnancies in the first trimester ${ }^{2}$. The typical onset is between 4 - 8 weeks of pregnancy and continue until 16-18 weeks of pregnancies ${ }^{3}$. Hyperemesis gravidarum (HG) is the severe form of this nausea \& vomiting in pregnancy and is associated with weight loss, ketonemia, ketonuria, electrolyte imbalances and profound volume depletion4. The actual incidence of Hyperemesis gravidarum has not been established, but has been reported to be $0.3-2 \%{ }^{5}$. It may persist throughout gestation in contrast to morning sickness, which usually decreases in the second trimester ${ }^{6}$. This on-going nausea and vomiting can significantly affect a women's ability to perform usual activities in family, social and occupational spheres ${ }^{7}$. It can cause temporary disability in a high proportion of employed women, and $25 \%$ of this pregnant women requires time off from work. As a consequence, some women chose to terminate desired pregnancy when symptoms are severe ${ }^{8}$. In addition to maternal effects, studies show that hyperemesis gravidarum can compromise fetal growth and outcome ${ }^{9}$.

The exact pathophysiologic mechanism from which Helicobacter pylori (H. Pylori) is believed to cause hyperemesis graviderum is unknown. The mechanism has been theoretically explained by increased accumulation of fluid caused by elevated steroid hormones in pregnancy, a shift in $\mathrm{pH}$ and change of $\mathrm{pH}$ in the gastrointestinal tract could result in the manifestation of a subclinical $\mathrm{H}$ pylori

1. Nilofar Yasmin, Assistant Professor ( Gynae \&Obs.), Shaheed Suhrawardy Medical College, Dhaka

2. Kohinoor Begum, Professor (Gynae \& Obs), Bangladesh Medical College, Dhaka

3. Santosh Kumar Saha, Junior Consultant (Pediatrics), National Centre for Control of Rheumatic Fever \& Heart Disease, Dhaka.

4. Kamrun Naher, Junior Consultant (Gynae \& Obs), District Hospital, Sherpur.

5. Dilip Kumar Ghosh, Assistant Professor (Gastroenterology), Shaheed Suhrawardy Medical College, Dhaka

6. Eva Rani Nandi, Registrar, ( Gynae \&Obs.), Shaheed Suhrawardy Medical College, Dhaka

7. Hasina Begum, Junior Consultant (Gynae \& Obs), Shaheed Suhrawardy Medical College, Dhaka

Correspondence

Dr. Nilofar Yasmin, Assistant Professor( Gynae \& Obs), Shaheed Suhrawardy Medical College,

Sher- E- Bangla Nagar, Dhaka-1207, Phone: 01819147555, Email: nilofar71@gmail.com

Conflict of interest: No conflict of interest

Contributions by authors: All authors contributed form protocol to write up of the article 
infection ${ }^{10}$. H. pylori, a gram negative, bacteria is associated with active and chronic gastritis. Such irritation causes nausea $\&$ vomiting. There are estimates that $50-65 \%$ of the developed countries \& $80-90 \%$ of the developing region of the world population are colonized with this bacteria but despite this high prevalence, not all infected individuals are clinically ill. However, although the exact mechanism leading to clinical symptoms is unclear but $\mathrm{H}$. Pylori positive patients show alterations in gastric function that are relieved after $\mathrm{H}$ pylori eradication ${ }^{11}$. Interestingly, Similar gastric alterations have been recorded in pregnancy, particularly 1st trimester. This regards the hypothesis that there is an association between hyperemesis gravidarum and $\mathrm{H}$ pylori, a claim found in the literature. The standard treatment for hyperemesis gravidarum includes fluid and electrolyte replacement, antiemetic therapy and in severe cases parenteral hyperalimentation. As a result of the uncertainty of the root cause of hyperemesis, physicians empirically treat a pregnant patient's nausea and vomiting without addressing the grounds for the patients ailments.

The major risk factor for infection with $\mathrm{H}$ pylori in the general population is low socioeconomic status of the family during childhood ${ }^{12}$. Its prevalence rate is higher in developing countries then the developed countries. The possible transmission routes may be oral-oral and feco-oral and iatrogenic transmission and Victorial spread $^{13}$. Being available, cheap and non invasive it is possible to detect helicobector pylori specific antibody in pregnant women ${ }^{14}$. Recently, using serology to detect $\mathrm{H}$ pylori several studies performed in different population, revealed a significantly high prevalence of Helicobector Pylori among women with hyperemesis graviderum ${ }^{15}$. We therefore examined whether seropositivity for IgG antibodies to H Pylori may be related to hyperemesis graviderum. In the case of this association, eradication of $\mathrm{H}$ pylori may help to treat hyperemesis graviderum which is a problem in the 1st trimester of pregnancy.

\section{Methodology}

This cross sectional study was conducted in the department of obstetrics and gynaecology, DMCH from January 2007 to December 2008 .The main objectives of this study was to evaluate the serum IgG against H.Pylori infection in Hyperemesis gravidarum patient. Pregnant women of gestational age 6-16 weeks with Hyperemesis gravidarum was taken as group A, while normal pregnant women with the same gestational age without hyperemesis gravidarum was included as group B. A total number of 82 pregnant women, 42 Group A \& 40 Group B were included in this study . Evaluation of the patient based on history, physical examination and investigations. HG patient with intractable vomiting, loss of body weight $>5 \%$, and volume depletion leading to dehydration were the enrollment criteria. Pregnancy with vomiting result from multiple pregnancy, trophoblastic disease, peptic ulcer and psychological disorder were excluded from the study. Under all aseptic precaution \& with informed written consent $2 \mathrm{cc}$ venus blood was collected from each patient and serum IgG against H. Pylori infection were measured by ELISA technique. Ethical permission was taken from institutional Review Board. Statiscal analysis was done by SPSS 16 window version. Appropriate statistical procedure was applied to find out association between hyperemesis gravidarum and helicobacter pylori. A $p$ value $<0.05$ was considered as significant.

\section{Results:}

Out of total 82 pregnant women 40 were hyperemesis gravidarum patients and 42 were control. Mean $( \pm \mathrm{SD})$ age in the hyperemesis gravidarum patients group was $23.75( \pm 4.63)$ years (range 18- 35) and that of control group was $23.62( \pm 4.05)$ years (range 18-32). Both the study and control groups were matched in regards to there age range. Mean gestational age of Group-A was 10.90 $( \pm 2.58)$ and Group-B was $12.67( \pm 3.00)$ and there was statistically significant difference between two groups ( $p$ values 0.006 ). Most of the patients of this study was primi gravida, Group-A was 29 (72.5\%) and Group-B was 28 $(66.7 \%)$. Mean body weight of Group-A was $38.40( \pm 6.13)$ and Group-B was $43.33( \pm 7.57)$, that difference was statistically significant ( $\mathrm{p}$ value- 0.002 ) and mean BMI of Group-A was 18.11( \pm 3.19$)$ and Group-B was 20.46 $( \pm 3.83)$. That difference was also statistically significant. ( $p$ values 0.00 ). Most of patients of the study and control group belonged to primary level education and most of them were housewife having low socioeconomic status.

Table 1: Demographic Profile

\begin{tabular}{llll}
\hline Variables & Group A(n=40) & Group B(n=42) & P value \\
\hline Age(years) & $09(22.5 \%)$ & $07(16.7 \%)$ & \\
$<20$ & $19(47.5 \%)$ & $23(54.8 \%)$ & \\
$<21-25$ & $10(25 \%)$ & $11(26.2 \%)$ & \\
$<26-30$ & $02(5 \%)$ & $01(2.4 \%)$ & \\
$>30$ & $23.75( \pm 4.63)$ & $23.62( \pm 4.05)$ & 0.89 \\
Mean age $( \pm$ SD) & & & \\
Gestational Age & $32(80 \%)$ & $24(57 \%)$ & \\
6-12 wks & $08(20 \%)$ & $18(43 \%)$ & 0.02 \\
$>12$ wks & $10.90( \pm 2.58)$ & $12.67( \pm 3)$ & \\
Mean $( \pm$ SD) & & & \\
Gravida & $29(72.5 \%)$ & $28(66.7 \%)$ & 0.56 \\
$\quad$ Primi & $11(27.5 \%)$ & $14(33.3 \%)$ & \\
$\quad$ Multi & & & \\
Weight \& BMI & $38.40( \pm 6.13)$ & $43.33( \pm 7.57)$ & 0.002 \\
Mean Weight $(\mathrm{kg})$ & $18.11( \pm 3.19)$ & $20.46( \pm 3.83)$ & 0.003 \\
Mean BMI & & & \\
Education & & $33(78.6 \%)$ & \\
Primary & $29(72.5 \%)$ & $6(14.3 \%)$ & \\
SSC & $7(17.5 \%)$ & $3(7.2 \%)$ & \\
HSC or More & $4(10 \%)$ & & \\
Occupation & & $36(85.7 \%)$ & 0.92 \\
Housewife & $34(85 \%)$ & $06(14.3 \%)$ & \\
Service holder & $06(15 \%)$ & $32(76 \%)$ & \\
Socioeconomic status & & & \\
Low & $34(85 \%)$ & $06(15 \%)$ & \\
Middle & & & \\
\hline
\end{tabular}


Previous history of hyperemesis gravidarum in the Group-A was $52.5 \%$ and Group-B was $07 \%(\mathrm{p}<.01)$, that is statistically highly significant. Serologically positive Helicobactor pylori infection was detected in 19 out of 40 pregnant women with HG ( $47.5 \%$ ) whereas in control group, only 8 out of 42 asymptomatic pregnant women were found to have positive antibody titers against Helicobactor pylori. The ratio of HP positivity in pregnant women with $\mathrm{HG}$ was significantly higher than asymptomatic control group (P-0.006).

Table-2. Association of previous history of hypermesis gravidarum in this study $(n=82$

\begin{tabular}{lcll}
\hline $\begin{array}{l}\text { Previous } \\
\text { H/O HG }\end{array}$ & $\begin{array}{l}\text { Group-A } \\
\mathrm{n}=40(\%)\end{array}$ & $\begin{array}{l}\text { Group-B } \\
\mathrm{n}=42(\%)\end{array}$ & P value \\
\hline Yes & $21(52.5 \%)$ & $03(07 \%)$ & $<0.01$ \\
No & $19(47.5 \%)$ & $39(93 \%)$ & \\
Total & $\mathbf{4 0 ( 1 0 0 \% )}$ & $\mathbf{4 2 ( 1 0 0 \% )}$ & \\
\hline
\end{tabular}

Table-3. Findings of antibody to Helicobactor pylori in Serum $(\mathbf{n}=\mathbf{8 2})$

\begin{tabular}{lccc}
\hline Serum IgG & $\begin{array}{c}\text { Group-A } \\
\mathrm{n}=40(\%)\end{array}$ & $\begin{array}{c}\text { Group-B } \\
\mathrm{n}=42(\%)\end{array}$ & P value \\
\hline Positive & $19(47.5)$ & $08(19)$ & 0.006 \\
Negative & $21(52.5)$ & $34(81)$ & \\
\hline
\end{tabular}

\section{Discussion}

Our study revealed higher H.pylori seropositivity in pregnant women with hyperenesis gravidarum than in controls (without hyperemesis). This result is similar to previous studies of Frigo, kocak, Jacoby \& several other studies that confirmed the association between H.pylori infection and $\mathrm{HG}$ and reporting a seropositive rate of more than $85 \%$ H.pylori infection in patients with $\mathrm{HG}^{10,15,17}$.

It is well doucumented that H.pylori is able to survive and multiply in the gastric environment, which is hostile to the growth of most bacteia ${ }^{16}$. When intraluminal acidity is diminished H.pylori is no longer able to colonize, possibly because of competeting organism . Therefore in pregnant women, delydration that is secondary to exchange of extracelluler and intracelluler fluid causes an increased acidity in the gestrointestanal tract and hence an increase in the activity of H.pylori ${ }^{16}$. In addition during pregnancy, due to steroid hormone, there is an increase in extracellular volume, which lead to change in PH. Some type of latent H.pylori infections are sensitive to these changes and this could lead to the menifestation of H.pylori infection ${ }^{10}$. This has been confirmed by clinical practice because usual therapeutic measures such as fluid replacement, administration of Vit B6, metoclopromide and bed rest that are routinely used for treating this condition do not result in any significant improvement of the symptoms ${ }^{4,17}$. Data from several studies strongly suggest that acute infection with H.pylori induces acute gastritis and as pregnancy progress, the host and the organism reach a state of equilibrium and intensity of inflammation decreases.

GI symptoms during pregnancy are more common in primigravida women, as well as in younger and less educated women ${ }^{18}$. This was matched with our study which revealed most of the HG (28 out of 40) occur in between $18-25$ years, these were about $72.5 \%$ (29 out of $40)$ of primigravida and about 34 out of $40(85 \%)$ were in low socioeconomic condition. In spite of this correlation there was no statisticlly significant relation between hyperemesis gravidarum to maternal age. Gravidity, socioeconomic status, educational status and occupation. This reason may be narrow range of reproductive age in this study (18-40 years), besides most pregnancies had occured in the narrow age rage to 20-35 years.

One of the most important points to consider in H.pylori infection in pregnancy is its transmission to the foetus ${ }^{17,19}$. Because the incidence of transmission is high and maternal ketosis occurring during dehydration of Hyperemesis Gravidarum should be avoided because of concern about the adverse effects of ketones, which are readily transported across the placenta, effect on fetal development. So it might be reasonable to eradicate the H.pylori infection as well as the Hyperemesis Gravidarum with suitable medications. Unfortunately however, therapy at the time of organogenesis is problematic. In our study we did not follow the patients for treatment and fetal outcome hence we have no information about the rate of transplacental transmission. More studies are needed to assess the effects of medical therapy for eradication of H.pylori and improvement of hyperemesis gravidarum. Recently the center for diseases control and prevention ${ }^{10}$ has made a recommendation to use metronidazole in all trimesters of pregnancy although this issue is a matter of discussion. Alternative medications such as the combination of amoxicillin and omeprazale do not appear to be promising and are still a matter for discussion ${ }^{17}$. There is a case reported by jacoby in which a women with persistent HG was successfully managed by administration of omeprazole, metronidazole and amoxicillin for a week. Previous pregnancis of this patients had been terminated due to hyperenesis gravidarum. Other case reports have suggested that the etiological role of H.pylori in hyperemesis gravidarum is due to a response to oral antibiotics. Psychological and social factors have also been thought to be important in patients with HG. Supportive psychotherapy including encouragement, explanation, reassurance and opportunity to ventilate emotions have been advocated as essential to a comprehensive management plan.

\section{Conclusion}

According to the findings of our study, H.pylori infection would seem to be an important factor in the exacerbation of $\mathrm{HG}$, but it does not seem to be the only cause of the disease. In regard to improved management of H.pylori infectons, we recommend that women who are considering pregnancy in the near future should be tested for H.pylori, and the infection should be brought under control prior to pregnancy. Also, prospective, randomized trials are needed in pregnant women with HG to determine whether there is association between $\mathrm{HG}$ and H.pylori infection by showing the effectiveness of pharmacotherphy. 


\section{References}

1.Lacroix R, Easton E, Melak R, Nausea and vomiting during pregnancy A prospective study of its frequency, intensity, and patterns of change. Am J Obstet Gynecol 2000; 182:931-937.

2.Klebanoff MA, Koslowe PA, Kaslow R, Rhoads GG. Epidemiology of vomiting in early pregnanmcy. Obstet Gynecol. 1985 Nov; 66(5): 612-616 3.Cunnigham G, Gant NF, Kenneth JL, Gilstrap LC, Hauth JC, Wenstrom KD. William's obstetrics. 21th ed. Mc Graw-Hill company; 2001. p. 1275-1276.

4.Leylek A, Cetin A, Toyaksi M. Hyperthyroidism in hy-premesis gravidarum. Int J Gynecol Obstet 1996; 55:34-37

5.Eliakim R, Abulafia O, Sherer DM. Hymeremesis gravidarum: a current review. Am J Preinatal 2000; 17(4): 207-218.

6.Cruikshank DP, Wigton TR, Hays PM. Maternal physiology in pregnancy. In: Gabbe SG, Niebyl JR, Simpson JL, editors. Obsterrics: normal and problem pregnancies. 3rd ed. New York (NY): Churchill Livingstone, Inc. 1996.p. 91-109.

7. O'Brien B, Naber S. Nausea and vomiting during pregnancy: effects on the quality of women's lives. Birth 1992; 19:138-43.

8. Mazzota P, Magee L, Koren G. Therapeutic abortions due to severe morning sickness: unacceptable combination. Can Fam Physician 1997; 43:1055-7.

9. Gross S, Librach C, Cecutti A. Maternal weight loss associated with hyperemesis gravidarum: a preductor of fetal outcome. Am J Obstet Gynecol 1989; 160:906-9.

10. Frigo P, Lang C, Reisenberger K, Kolbl H, Hirshl AM, Hyperemesis gravidarum associated with Helicobacter pylori seropositivity. Obstet Gynecol. 1998 Apr; 91(4):615-617.
11. Lin Z, Chen JDZ, Parolisi S, Shifflett J, Peura DA, McCallum RW. Prevalence of gastric myoelectrical abnormalities in patients with nonulcer dyspepsia anjd $\mathrm{H}$ pylori infection: resolution after $\mathrm{H}$ pylori eradication. Dig Dis Sci 2001;46:739-45.

12. Reshetnikov OV, Denisova DV, Zavyalova LG, et al. Helicobacter pylori seropositivity among adolescents in Novosibirsk, Russia: prevalence and associated factors. J Pediatr Gastroenterol Nutr 2003; 36:72-6.

13.Fenogliar Preiser CM, Naf tainger AE, Stemmerman GN, 2nd Gastrointestinal prothology, Philadelphia: Lippin Cott- Raven publishers, 1999, P. 153-236

14.Blecker U, Lanciers S, Hauser B, Metha DI, Vandenplas Y. Serology as a valid screening test for Helicobacter pylori infection in asymptomatic subject'. Arch Pathol Lap Med 1995; 119:30-32

15.Jacoby EB, Porter KB: Helicobacter pylori infectoin and persistent hyperemesis gravidarum. Am J Perinatol, 1999; 16(2): 85-8

16.Blaser M, Berg D. H. Pylori genetic diversity and risk of human disease J. Clin Invest, 2001; 107:767-73.

17.Kocak I, Akcan Y, Ustun C, et al. Helicobacter pylori seropositivity in patients with hyperemesis gravidarum Int J Gunecol Obstet 1999;66(3): 251-4.

18.Wu CY, Tseng, JJ Chou MM, Lin SK, Poon SK, Chen GH. Correlation between Helicobacter pylori infection and gastrointestinal symptoms in pregnancy. Adv Ther 2000;17:152

19.Blecker U, Lanciers S, Vandenplas Y. Evaluotion of Helicobacter pylori positivity in infants born from positive mothers. J Pediar Gastrienterol Nutr 1994:19-87-90

20.Creasy R, Resnik R, Maternal Fetal Medicine. 4th edition. Philadelphia: W.B Saunders Company; 1999. p. 1042-1044. 